\title{
Intangible Assets, Intellectual Property and the Misreporting of Financial Events
}

\author{
Jeffrey E Jarrett* \\ Department of Management Science, University of Rhode Island, USA
}

\begin{abstract}
Problems associated with financial reporting of intellectual property rights (IPR) and similar intangible assets are not reported in the same manner as those assets are tangible. Although accounting uses the principle of "conservatism" to evaluate the economic value of all assets, the present rules specified by the Financial Accountants Standards Board (FASB) do not follow the development of accounting principles associated with timing of financial events. This study refers to and utilizes the established methodology in financial reporting literature to develop better methods for estimating the monetary value of IPR and other intangible assets. The estimation methodology, also, will not be a detrimental factor in determining the value of these intangible assets during mergers, acquisitions and the development of new IPR and intangibles.
\end{abstract}

Keywords: Intellectual property rights; Intangible assets; Estimation; Mergers and acquisition

\section{Introduction}

Deschow [1] postulated that the use of accrual based accounting methods increased the capability of accounting based forecasts to improve the ability to measure firm performance reflected in returns to equity investments. The argument was that cash flow accuracy is expected to suffer from matching, realization and other timing problems concerning the recognition of costs and revenues. Accuracy of financial reports compared methods of forecasting accounting earnings seeking to learn how forecast models can be compared and possibly improved to produce more accurate results [2-5]. Questions posed included sources of accuracy, but accrual accounting was not considered the most important source of inaccurate results. However, no one established a theoretical link between sources of inaccuracy and the matching principle and the accuracy of financial analysts' forecasts although many studied the problem [2,6-9]. Financial reports containing these forecasts of cash flow and rates of return are subject to fluctuations in the interpretation of timing principles utilized by accountants. However, Gu and Wang [10] brought up the possibility of another source of inaccuracy in the forecast of rates of return, cash flow and earnings.

Theses researchers concluded that there is a substantial relationship between analysts' forecasts and the magnitude and value of intangible assets. Intangible assets were not considered in the forecasting method discussed by the researchers in their many and detailed studies. The value of intangible assets produces a great source of error if they are not considered in the forecasting methods utilized by analysts in the production of cash flow, rates of return and earnings per share forecasts. When adjustments for intangible assets are included in the analyst's forecasts, $\mathrm{Gu}$ and Wang stated that The rise of intangible assets in size and contribution to corporate growth over the last two decades poses an interesting dilemma for analysts. Most intangible assets are not recognized in financial statements, and current accounting rules do not require firms to report separate measures for intangibles [10]. Intangibles include trademarks, brand names, patents and similar properties that have value but are generally not listed on financial reports of firms. Many of these items are technology based and are very important in financial decisions such as in mergers and acquisitions. They are an intricate in the growth of firms and therefore are shown to be related in the statistical sense to the overall estimates made by accounting analysts.

In another study concerning analysts' forecasts, Lambert et al. [11] found that the association between EPS forecast, growth rates forecast error and measures of technological conditions in the firm's industry. They found as the forecast horizon increases, the technological conditions and current EPS are statistically associated with analysts' forecasts. Long horizon creates the conditions for within one to conclude that interactions between technological conditions and current EPS are associated with analysts' EPS and growth forecasts. This conclusion align itself with Jung et al. [12] who suggested that analysts' growth forecasts effect efforts to evaluate analysts' forecasts may produce optimistically biased long-term forecasts. Since intangible assets which are often technology based are taken up more of the balance sheet of many firms, it is likely that analyst's forecasts may produce less accurate predictions of earnings, cash flow and rate of return. The conclusions of Deschow [13] become less important. Balance sheets usually have little or no involvement with the value of intangibles although there are some practices by accountants are still used.

\section{Intellectual Property and Traditional Accounting Methodology}

As noted by the timing of recognition of revenue for IPR in financial statements of ten are not featured in merger and acquisition activity [3,14-21]. The financial accounting standards board (FASB) provides for such activities, however, they are often ignored due to their evasiveness or are not fully informational in there normally structured rules. Recognizing future performance is a goal of matching

*Corresponding author: Jeffrey $\mathrm{E}$ Jarrett, $\mathrm{PhD}$, Professor, Department of Management Science, University of Rhode Island, USA, Tel: +1 401-874-1000; E-mail: jejarrett133@gmail.com

Received October 27, 2017; Accepted November 13, 2017; Published November 23, 2017

Citation: Jarrett JE (2017) Intangible Assets, Intellectual Property and the Misreporting of Financial Events. J Bus Fin Aff 6: 300. doi: 10.4172/21670234.1000300

Copyright: @ 2017 Jarrett JE. This is an open-access article distributed under the terms of the Creative Commons Attribution License, which permits unrestricted use, distribution, and reproduction in any medium, provided the original author and source are credited. 
and timing but are unrelated to recognizing cash flow and similar items in the historical performance of a firm. Non-profit entities often do not use accrual rules at all since the goal of these are related to achieving high rates of return. Often IP rights for non-profits would differ from the same item for profit maximizing entities since the goal of seeking high rates of return does not enter the strategic planning process for non-profits. The purpose here is to consider IP as intangible assets as a product of intellect that law protects from unauthorized use by those not responsible for the IP rights. Hence, IP rights are characterized as the protection of distinguished signs such as trademarks for goods and services, patents, and other similar items which are under protection from unauthorized use. This includes art, music, creations by authors including the authorship of computer software and similar items such as discoveries, inventions, phrases, symbols and design. Obviously, a writer and conductor of Music such as Leonard Bernstein, Daniel Barenboim and James Levine would have created IP that differ greatly from Physicists such as Lisa Meitner, Nils Bohr or Albert Einstein.

Presently, accounting suggests two methods to determine the value of IP rights to produce better estimates of from accounting analysts' forecasts. The convention of the "lower of cost or market" is based on the rule of conservatism in valuing assets to anticipate future losses instead of future gains. The policy tens to understate rather than overstate the value of net assets and could therefore lead to an understatement of income, cash flow, earnings and rates of return. The purpose of this study and its conclusive result is to neither understate nor overstate cash flow so as to produce a rate of return on cash flow that is commensurate with the goal producing accurate prediction of cash flow and its rate of return for financial and decision making purposes. Stated differently, the purpose is not to violate accounting policy but to insure the mergers and acquisitions (M\&A) that cash flow is estimated properly. Traditionally, when accounting writes policy about intangible assets as a residual. By residual, they mean a buyer is ready to value a firm in excess of the value of the tangible assets. This value is often referred as Goodwill [22] which is an imperfect method. This notion of goodwill is estimated as a residual value. If the valuation of intangible property is imperfect since it considers part of the solution of a bargaining process. In this case, the buyer and seller may have different market power which greatly affects the residual of the bargaining process and produces an imperfect or biased estimate of the value of the 9 intangible assets. One may examine the case of the sale of "Superman" by struggling comic artists to a much larger corporate power who could market the character to "Comic Books", Television and the Film Industry. The nearly destitute conditions of the original artists who created the intangible product could never cope with the business and marketing (power) of those who purchased the name "Superman." Thus, goodwill becomes a vague valuation system that justifies the bringing of data analysis and science into the valuation process.

Another solution suggested during the M\&A process is to simply list the patents, trademarks, brands and similar items of IP in the financial reporting of the firm. Following this initiative and suggestion of the accounting principles board provide little aid concerning the economic value of IP rights and products for a firm during the M\&A events. In the final step of the problem the evaluation may conclude influence relating to the biases of the reading of the financial reports. Such biases of IP occurred often with works of Meitner, Einstein and Bohr. Whereas, at least Einstein and Bohr received Nobel Prizes which did have wealth, but Meitner perhaps due to her gender and religious preference never received the award the others were given. The three conductors and composers of music there was no economic award from the Nobel Prize Committees. Accountants forecast the overall rate of return for a firm but do not ignore the convention of "conservatism." Accounting practice values the IP rights for a firm each year for each and every IP right under consideration. The principle of Goodwill is not to be used during M\&A activity to account for the value of IP rights. IP may induce greater asset values but also effects the rate of return on cash flow because the denominator of the rate of return will change. To understand the gravity of ignoring or improperly valuing IP rights see Jarrett $[23,24]$. This result debated previously by Brief and Owen, Pappas' and Brief [14,16,21] indicated that including earnings risk may not fully reflect all risk in estimating earnings, but at least, reflects that part of risk from the variation in earnings.

\section{Estimating Cash Flow Attributable to Intangible Assets}

Estimation theory in accounting is consistent with traditional accounting and assumes the objective by becoming part of the foundation of modern account [25]. Estimation methods are cost based allocation procedures and are utilized to express the accounting rate of return. In using accounting information to predict the value of intangible assets and the cash flow associated with rates of return on cash flow. Based on the notion and observable evidence there is a relation between the increase in the value intangible assets and the cash flow associated with a firm's assets. Since a purpose of accounting is to provide information for predicting parameters, i.e. the rate of return for a decision model, a method for relating information is estimation theory.

Without repeating the general model developer by Brief and Owen [25] and implemented in another allocation model by Jarrett [18], we may observe the set of allocation methods, that the allocation system is, cash flow attributable to estimating the value of intangible assets usually results in error in estimating the rate of return since the rate of growth is not predicted precisely.

\section{An Example of Estimating a Monetary Value of IPR}

To illustrate the case of monetarizing IPR and other intangible assets, let us consider the specific problem of a firm purchasing IPR through a direct acquisition and the issuance of new debt as part of its holdings to finance the items. Obviously, the ratio of common equity to total capital stock will be changed during the financial operation. In turn, the effects of financial leverage on total financial risk will also be part of the problem. The rate of return to common shareholders is related to the measure of financial risk utilized in any decision of this type. We assume that the firm is motivated is finance the acquisition by leverage instead of issuing new common share nor a strict loan from a financial institution or similar institution is the result of an economic optimization policy. Define T as the sum of debt and common stock. To illustrate simply, preferred share and other financial instruments are valued at zero to avoid complications that my hinder the explanation. $S$ is the monetary value of outstand common and $\mathrm{D}$ is amount oi debt; $\mathrm{X}$ the amount of earning in a future time period. $\mathrm{X}$ is a random variable and $\mathrm{E}(\mathrm{X})$ is the mean of the random variable, $\mathrm{V}(\mathrm{X})$ the variance and $\mathrm{S}(\mathrm{X})$ the square root or standard deviation. The cost of the debt per dollar is I; the interest rate. The mean earnings per dollar of $S$ is

$$
\mathrm{E}(\mathrm{Y})=\mathrm{E}(\mathrm{X}) / \mathrm{S}=\mathrm{E}(\mathrm{X}) /(\mathrm{T}-\mathrm{D})
$$

Note that $\mathrm{Y}$ is also a random variable with mean $\mathrm{E}(\mathrm{Y})$. Mean (or expected) earning is defined as follows:

$\mathrm{E}\left(\mathrm{X}^{\prime}\right)=\mathrm{E}(\mathrm{X})-\mathrm{iD}$ for $\mathrm{D}>0$;

Hence, $\mathrm{E}\left(\mathrm{X}^{\prime}\right)=\mathrm{E}(\mathrm{X})$, for $\mathrm{D}=0\left(2^{\prime}\right)$ 
The variance of total earnings is

\section{$\mathrm{V}\left(\mathrm{X}^{\prime}\right)=\mathrm{V}(\mathrm{X})$ for $\mathrm{D} \geq 0$ (iD is a constant) $\left(2^{\prime}\right)$}

The financial decision-optimum is to fund the purchase is an example of decision analytics where the decisions are to substitute debt for common stock or not to substitute debt. Using data analytical language, for this decision problem the states of nature are defined by

\section{$\mathrm{E}(\mathrm{X})>\mathrm{ID}$ or $\mathrm{E}(\mathrm{X}) \leq \mathrm{ID}$}

We define the opportunity loss function as an integral approximation the firm's view towards choosing a non-optimal decision. No loss occurs when earnings are great than the cost of debt since management will benefit from the strategy of leverage financing.

As an example consider cash flow to be greater than the cost of debt management and in turn the loss function would change reflecting the goal of optimum decision analytics. The basic structure of the acquisition strategy would not change except for the substitution of cash flow for earnings. To calculate the opportunity loss function associated with this strategy, we estimate some probability density function (PDF) that approximates the PDF for future earnings. Before we consider all PDFs, let the firm focus on the normal distribution or $\mathrm{T}$-distribution having a very large number of degrees of freedom which approximates the standard normal distribution. The opportunity loss becomes at breakeven $\left(\mathrm{X}_{\mathrm{b}}\right)$ becomes

$$
\mathrm{X}_{\mathrm{b}}=\mathrm{E}\left(\mathrm{X}^{\prime}\right)-\mathrm{Z}\left(\left(\mathrm{S}\left(\mathrm{X}^{\prime}\right)\right)\right.
$$

$\mathrm{Z}$ refers to the normal fiducial deviate; and $\mathrm{S}\left(\mathrm{X}^{\prime}\right)$ the standard deviation. By rearrangement, we find $\mathrm{E}(\mathrm{X})=\mathrm{E}\left(\mathrm{X}^{\prime}\right)-\mathrm{iD}$. The next step is to determine the size and distribution of the loss function for the distribution of future earnings which is all in line with objectives of the timing of the realization revenues discussed before Jarrett (1971 and others). In Table 1 , we preview one method to estimate the monetary value of IPR. The $\mathrm{E}(\mathrm{X})$ is $\$ 5000$ and the $\mathrm{S}(\mathrm{X})$ increases by given amounts (\$100). Column 3 contains the cost of debt of $\$ 4000$. The $\mathrm{Z}$ calculation is accomplished column 4 with column 5 containing the cumulative normal probability. In turn, the IPR monetary value is simply the normal probability multiplied by $\mathrm{E}(\mathrm{X})$ and is contained in column 6 . The IPR\$ is thus calculated for a variety of circumstances [26]. In summary, the example demonstrates that estimation theory in financial accounting is a fundament portion of correcting financial reporting data such that analysts now have a complete set of data work with when making forecasts and other decisions. Our findings do not dispute that of others. Instead it corroborates many discussions of the lack of determining the monetary or economic value of IPR. In one last thought others including Pakes and Shankerman [27] found that values of these intangibles decrease and they become desolate and less useful over time requiring reestimation.

\section{Summary and Conclusions}

Problems associated with analysts' forecasts of earnings, cash

\begin{tabular}{|c|c|c|c|c|c|}
\hline $\mathbf{E}(\mathbf{X})$ & $\mathbf{S}(\mathbf{X})$ & Debt Cost & $\mathbf{Z}$ & Prob Z & IPR\$ \\
\hline 5000 & 400 & 4000 & 2.5 & 0.99379 & 4968.95 \\
\hline 5000 & 500 & 4000 & 2 & 0.97725 & 4886.25 \\
\hline 5000 & 600 & 4000 & 1.66667 & 0.95221 & 4761.05 \\
\hline 5000 & 700 & 4000 & 1.42857 & 0.923436 & 4617.18 \\
\hline 5000 & 800 & 4000 & 1.25 & 0.89435 & 4471.75 \\
\hline 5000 & 900 & 4000 & 1.11111 & 0.86674 & 4333.7 \\
\hline
\end{tabular}

Table 1: Monetarization of IPR changes in standard deviation of earnings. flow and rates of return continue often because intangible assets are either not estimated properly or not even considered in the forecasting process at all. No matter that rules of accrual accounting are utilized or miss utilized, error may exist in analysts' forecast even when one properly uses forecast methods. If the influence of intangible assets often referred to as intellectual property continue to grow sand not be reported in financial statements, the error associated with the growth in these assets will correlate with the magnitude of errors in forecast. Even testing finding that use of accruals will improve analysts' forecast accuracy is insufficient in recognizing that increases in cash flow is related to the growth and use of intellectual property

The purpose in this study is to employ estimation theory in improving analyst's forecasts because it will recognize the value of intellectual property rights and other intangible assets which are often the major source of error because they are ignored. Estimation theory has a long history in financial reporting because it has shown that matching and realization methods are in reality the same problem. Timing and allocation problems basically similar principles and only elementary accounting textbooks would present them as different. We should note that the allocation problems in financial accounting are already known as noted in the review of Thomas.

Note, also, that overestimation of cash flow resulting in the overestimate of income inflates rates of return for firms. Rates of return are still used for making decisions concerning investments in and the abandonments of projects. Analysts' forecast is particularly important in decisions concerning portfolio management as well.

\section{References}

1. Deschow PM, Schrand CM (2004) Earnings Quality. Research Foundation Books 3: 1-152.

2. Brandon C, Jarrett JE (1974) Accuracy of Financial Forecasts. Financial Review 9: 1-45.

3. Jarrett JE (1983) The Rate of Return from Interim Financial Reports. Journal of Business Finance and Accounting 10: 289-294.

4. Jarrett JE, Khumawala SB (1987) A Study of Forecast Error and Covariant Time Series to Improve Forecasting for Financial Decision Making. Managerial Finance 13: 20-24

5. Jarrett J (1992) An Economical Method for Correcting Forecasting Error American Journal of Business 7: 55-58.

6. Clement MB (1999) Analyst forecast accuracy: Do ability, resources, and portfolio complexity matter? Journal of Accounting and Economics 27: 285-303.

7. Gu Z, Wu JS (2003) Earnings skewness and analyst forecast bias. Journal of Accounting and Economics 35: 5-29.

8. Ramnath S, Rock S, Shane PB (2008) The financial analyst forecasting literature: A taxonomy with suggestions for further research. International Journal of Forecasting 24: 34-75.

9. Groysberg B, Healy P, Nohria N, Serafeim G (2011) What factors drive analyst forecasts? Financial Analysts Journal 67: 18-29.

10. Gu F, Wang W (2005) Intangible Assets, Information Complexity and Analysts Earnings Forecasts. Journal of Business Finance and Accounting 32: 16731702.

11. Lambert D, Matolcsy Z, Wyatt A (2015) Analysts' earnings forecasts and technological conditions in the firm's investment environment. Journal of Contemporary Accounting and Economics 11: 1-46.

12. Jung B, Shane PB, Yang YS (2012) Do Financial Analysts' Long-Term Growth Forecasts Matter? Evidence from Stock Recommendations and Career Outcomes. Journal of Accounting and Economics 51: 1-2.

13. Deschow PM (1994) Accounting earnings and cash flows as measures of firm performance: The Role of accounting accruals. Journal of Accounting and Economics 18: 3-42. 
Citation: Jarrett JE (2017) Intangible Assets, Intellectual Property and the Misreporting of Financial Events. J Bus Fin Aff 6: 300. doi: 10.4172/21670234.1000300

14. Brief R, Owen J (1969) A Note on Earnings Risk and the Coefficient of Variation. Journal of Finance 24: 901-904.

15. Brief R, Owen J (1970) The Estimation Problem in Financial Accounting. Journal of Accounting Research 8: 167-177.

16. Brief R (1977) A Note on the Inclusion of Earnings Risk in Measures of Return: A Reply. Journal of Finance 32: 1367.

17. Jarrett JE (1971) The Principles of Matching and Realization as Estimation Problems. Journal of Accounting Research 9: 378-382.

18. Jarrett JE (1974) Bias in Adjusting Asset values for Changes in the Price Level: An Application of Estimation Theory. Journal of Accounting Research 12: 63-66.

19. Roberts C, Roberts E (1970) Exact Determination of Earnings Risk by the Coefficient of Variation. Journal of Finance 25: 1161-1165.

20. Barnea A, Sadan S (1974) On the Decomposition of the Estimation Problem in Financial Accounting. Journal of Accounting Research 12: 197-203.

21. Pappas JL (1977) A Note on the Inclusions of Earnings Risk in Measures of Return: A Comment. Journal of Finance 32: 1363-1366.
22. White GI, Sondhi AC, Fried D (1994) The Analysis and Uses of Financial Statements. (3rdedn), John Wiley, New York.

23. Jarrett JE (2016) The Problems of Accounting Reporting False Information and Estimation. Intel Prop Rights, S1: 007.

24. Jarrett JE (2017) Intellectual Property Valuation and Accounting. Intel Prop Rights 5: 181.

25. Brief R, Owen J (1968) A Least Squares Allocation Model. Journal of Accounting Research 23: 193-199.

26. Jarrett JE (2017B) Intellectual Property and the Role of Estimation in Financial Accounting and Mergers and Acquisition. S.F. Intellectual Property Rights 1 : $1-8$.

27. Pakes A, Shankerman M (1984) The Rate of Obsolescence of Patents, Research Gestation Lags, and the Private Rate of Return to Research Resources. In R\&D Patents, and Productivity, Zvi Griliches (ed.), University of Chicago Press, pp: 73-88. 